\title{
Correction to: An empirical model for educational simulation of cervical dilation in first stage labor
}

\author{
Silvano R. Gefferie ${ }^{1 \dagger}$, Anouk W. J. Scholten ${ }^{1 \dagger}$, Kim A. E. Wijlens ${ }^{1 \dagger}$, M. Luísa Ferreira Bastos ${ }^{2}$, \\ M. Beatrijs van der Hout-van der Jagt ${ }^{3}$, Hans Zwart ${ }^{4}$ and Willem L. van Meurs ${ }^{5^{*}}$
}

\section{Correction to: Adv Simul 3:9 (2018) \\ https://doi.org/10.1186/s41077-018-0068-3}

Continuing work on a recently published empirical model for educational simulation of cervical dilation [1] resulted in identification of errors in the code implementing this model. Numerical values of three parameters and one state variable had to be updated to obtain the original simulation results with corrected code. The errors identified in the original code included incorrect assignment of the value of the parameter that governs the dilation increase due to pressure exerted by the fetus on the cervix, a discrete time step specified in hours with parameters using minutes as a time reference, numerical integration of a static equation, and unnecessary capping of the uterine contraction amplitude. In the MATLAB code listed in the appendix, these errors are corrected. To obtain the originally published simulation results for cervical dilation, three parameter values had to be adjusted, see Table 1.
On closer inspection, it was also found that the value of the parameter $\mathrm{AFR}_{50}$ of $7.9 \mathrm{mU} / \mathrm{min}$ in [2] was incorrectly assigned to $\mathrm{P}_{6}$, which is a concentration in $\mathrm{mU} / \mathrm{mL}$. In semi-steady state it can be derived from Eqs. $(2,3)$ of the original paper that the updated value listed in Table 1 corresponds to the concentration in steady state on an infusion of magnitude $\mathrm{AFR}_{50}$ for the given pharmacokinetic parameters $P_{3}$ and $\mathrm{P}_{4}$. The evolution of drug mass over time is given by the pharmacokinetic equation, Eq. (4) of the original paper. In semi-steady state, drug mass is proportional to infusion rate. This value is assigned to $\mathrm{m}$ (0) in Table 1. Simulation results for cervical dilation using corrected code and adjusted numerical values match the results presented in the original paper in good approximation. The conceptual model and all presented model equations stood up to this additional scrutiny.

\footnotetext{
The original article can be found online at https://doi.org/10.1186/s41077018-0068-3.

* Correspondence: vanmeurs@orange.fr

'Silvano R. Gefferie, Anouk W. J. Scholten and Kim A. E. Wijlens contributed equally to this work.

${ }^{5}$ Cardiovascular and Respiratory Physiology Group, Faculty of Science and Technology, University of Twente, Drienerlolaan 5, 7522 NB Enschede, The Netherlands

Full list of author information is available at the end of the article
} licence and your intended use is not permitted by statutory regulation or exceeds the permitted use, you will need to obtain permission directly from the copyright holder. To view a copy of this licence, visit http://creativecommons.org/licenses/by/4.0/ The Creative Commons Public Domain Dedication waiver (http://creativecommons.org/publicdomain/zero/1.0/) applies to the data made available in this article, unless otherwise stated in a credit line to the data. 
Table 1 Original and updated model parameters. See [1] for a detailed description of the individual parameters and references to numerical values

\begin{tabular}{llll}
\hline & original value & updated value & units \\
\hline$P_{1}$ & 0.740 & & $\mathrm{mU} / \mathrm{min}$ \\
$P_{2}$ & 50.0 & 1.70 & $\mathrm{mU} /(\mathrm{min} \mathrm{cm})$ \\
$P_{3}$ & 0.0693 & & $1 / \mathrm{min}$ \\
$P_{4}$ & 18,700 & & $\mathrm{~mL}$ \\
$P_{5}$ & 0.500 & 0.00610 & $1 / \mathrm{min}$ \\
$P_{6}$ & 7.90 & & $\mathrm{mU} / \mathrm{mL}$ \\
$P_{7}$ & 1.11 & & $\mathrm{dimensionless}$ \\
$P_{8}$ & 40.0 & & $\mathrm{~mm} \mathrm{Hg}$ \\
$P_{9}$ & 40.0 & & $\mathrm{~mm} \mathrm{Hg}$ \\
$P_{10}$ & $1.00 \times 10^{-3}$ & & $\mathrm{~cm} / \mathrm{min}$ \\
$P_{11}$ & $1.90 \times 10^{-2}$ & $4.00 \times 10^{-4}$ & $\mathrm{~cm} / \mathrm{mm} \mathrm{Hg}$ \\
$m(0)$ & 273 & 59.0 & $\mathrm{mU}$ \\
$d(0)$ & 2.0 & & $\mathrm{~cm}$ \\
\hline
\end{tabular}

\section{Appendix}

\section{Corrected and verified Matlab code}

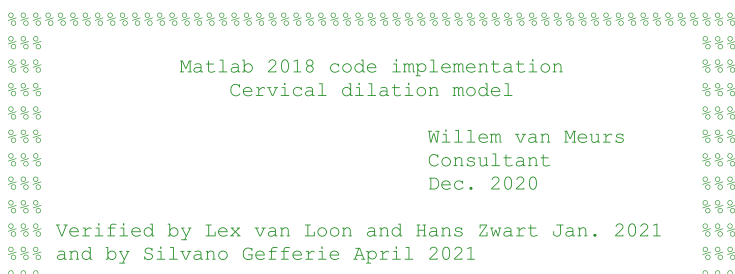

응응 and by Silvano Gefferie April 2021 응

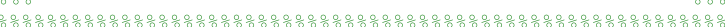

Algorithm implicit in the included comments.

Symbols as in Gefferie et al. 2018

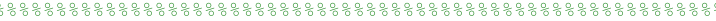
clear

DEFTNTTON OF STMUIATTON TTMB

$t=(n-1) * T$ Discrete time $n$ also serves as Matlab vector index

$t=(n-1) \times I$ Discrete time

$\operatorname{tmin}=0.0 ; \quad \frac{\mathrm{min}}{2}$

$t \max =1050.0 ; \quad \frac{\mathrm{min}}{2}$

$\mathrm{T}=1 ; \quad \frac{\circ}{0}$ integration step size (min)

$\mathrm{N}=$ round $((\operatorname{tmax}-\mathrm{tmin}) / \mathrm{T})+1$;

for $\mathrm{n}=1: \mathrm{N}$

end

$t(n)=(n-1) * T$

NUMERICAL VALUES MODEL PARAMETERS

$\mathrm{P} 1=0.740$

$\mathrm{P} 2=1.70$;

$\mathrm{P} 3=0.0693$;

$P 4=18700 ;$

$\mathrm{P} 5=0.500$;

$\mathrm{P} 6=0.00610$;

$\mathrm{P} 7=1.11 ;$

$\mathrm{P} 8=40.0 ;$

$\mathrm{P} 9=40.0$;

$\mathrm{P} 10=1.00 * 10^{\wedge}-3$;

$\mathrm{P} 11=4.00 * 10^{\wedge}-4 ;$

STATE VARTABIF INTTIALIZATTON

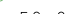

d=2.00

क् $\mathrm{cm}$

$\therefore$ RUN-TIME EQUATIONS

for $\mathrm{n}=1: \mathrm{N}$

$\mathrm{r}=\mathrm{P} 1+\mathrm{P} 2 * \mathrm{~d}$;

$n m=(1-P 3 * T) * m+T * r ; \quad \quad \frac{\circ}{2}(n+1)$

$\mathrm{C}=\mathrm{m} / \mathrm{P} 4$;

$S=\mathrm{C}^{\wedge} \mathrm{P} 7 /\left(\mathrm{P} 6^{\wedge} \mathrm{P} 7+\mathrm{C}^{\wedge} \mathrm{P} 7\right) ; \quad$ 응 sigmoid

$\mathrm{f}=\mathrm{P} 5{ }^{*} \mathrm{~S} ;$

$\mathrm{a}=\mathrm{P} 8+\mathrm{P} 9{ }^{*} \mathrm{~S} ;$

$\mathrm{nd}=\mathrm{d}+\mathrm{T}^{\star}\left(\mathrm{P} 10+\mathrm{P} 11 \mathrm{f}^{\star} \mathrm{a}\right) ; \quad$ \% $\mathrm{d}(\mathrm{n}+1)$

if $\mathrm{nd}>10.0$ cap to $10 \mathrm{~cm}$

end

nd $=10.0$;

output $(n)=d$;

$\mathrm{m}=\mathrm{nm}$;

$\mathrm{d}=\mathrm{nd}$;

end

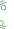

GRAPHICAL OUTPUT

figure (1)

plot ( $t$, output)

axis ([tmin tmax 2 10])

grid on

xlabel ('time in min')

ylabel ('dilation in cm')

Acknowledgements

The authors thank Eva Kleinveld and Lex van Loon for their help in identifying and correcting the programming errors.

Author details

${ }^{1}$ Technical Medicine, University of Twente, Drienerlolaan 5, 7522 NB Enschede, The Netherlands. ${ }^{2}$ Animals in Science, Eurogroup for Animals, Hertogstraat 29, 1000 Brussels, Belgium. ${ }^{3}$ Department of Signal Processing 
Systems, Faculty of Electrical Engineering, Eindhoven University of Technology, PO Box 513, 5600, MB, Eindhoven, The Netherlands.

${ }^{4}$ Department of Applied Mathematics, Faculty of Electrical Engineering, Mathematics, and Computer Science, University of Twente, Drienerlolaan 5, 7522 NB Enschede, The Netherlands. ${ }^{5}$ Cardiovascular and Respiratory Physiology Group, Faculty of Science and Technology, University of Twente, Drienerlolaan 5, 7522 NB Enschede, The Netherlands.

\section{Published online: 01 October 2021}

\section{References}

1. Gefferie SR, Scholten AWJ, Wijlens KAE, Ferreira-Bastos ML, van der Hout-van der Jagt MB, Zwart $\mathrm{H}$, et al. An empirical model for educational simulation of cervical dilation in first stage labor. Adv Simul. 2018;3:9 1-4.

2. Lobo MF, Bastos LF, van Meurs WL, Ayres-de-Campos D. A model for educational simulation of the effect of oxytocin on uterine contractions. Med Eng Phys. 2013;35(4):524-31. https://doi.org/10.1016/j.medengphy.2 012.06.021. 